\title{
LEVANTA VÔO SIRIPIPI
}

\author{
David Mestre
}

RESUMO: Coming from Certeza and belonging to Diáspora, Orlanda Amarílis does not make concessions when dealing with national identity and self cultural orientation what is stressed in the images of the foreign space as well as the images of the foreigner in the Archipelago. This article proposes a reflection on those images where text and cultural context amalgamate in the construction of an identity process, within a discursive practice which ruptures the pact of Realism celebrated above all with alterity in order to unveil the self through mythic tradition where the individual assumes the colective character. This is now the author's work published during the post-independence period is inscribed in the culture, in the History and in the social evolution of an Archipelago which makes slaves and of a foreigner who interferes and puts people in a marginal condition, thus reinforcing nationalism.

PALAVRAS-CHAVE: crónica, intertextualidade, dados biográficos.

Ernesto Lara Filho, consensualmente reconhecido como fundador da crônica angolana, que nos idos de 50 e 60 ganhou extraordinária popularidade, afirmando-se como privilegiado encontro de confluências e intertextualidades no espaço da língua portuguesa, com relevo para o triângulo Angola/Brasil/Portugal - tradições literárias por onde peregrinou em busca de um modelo de inconfundível sabor nativo - tinha 44 anos quando em Fevereiro de 1977 faleceu no Huambo, que lhe deu sepultura em manhã triste e chuvosa.

Foi igualmente notável poeta na linha do romantismo revolucionário, de forte acento regional, de meados do século, inconformista nato, repórter e correspondente que ouviu o seu nome apregoado pelos ardinas, figura legendária e controversa de aventureiro, boêmio e declamador de subúrbio, e antes e depois de tudo, como gostava de afirmar, regente agrícola e desvelado apicultor.

Nestas facetas e características cabe um vulto apaixonante no contexto do idioma que praticou a preceito e à consignação dos clássicos e

David Mestre é escritor angolano, vinculado a empreendimentos artísticos culturais, um dos responsáveis pelo Semanário de Luanda e Associação Nacional dos Escritores de Angola. 
das muitas, sortidas e sempre circunstanciais referências do escaldante percurso deste escritor que se definia como uma espécie de ilhota isolada no meio do temporal dos mares do sul que é o continente africano dos nossos dias. Mas isso me dá a vantagem de ser um porto de abrigo de todas as correntes que se entrechocam no vendaval do momento.

Reproduzidas do livro Crônicas da Roda Gigante (LARA FILHO, 1990), posto a circular com chancela da editora Afrontamento, do Porto, estas considerações ilustram uma vocação consumida no furacão do postguerra, com seu avassalador envolvimento mitológico, onde as aspirações independentistas dos filhos das colônias caucionavam todas as contestações. Menino de Benguela, estudante de Coimbra, irmão da festejada poeta e médica nacionalista Alda Lara, após fulgurante passagem pelo jornalismo luandense, segue o destino do exílio.

Começa aí a via sacra que conduziria Lara Filho a atravessar os Pirineus, tempo depois de voltar a Portugal para prosseguir estudos de Direito. O seu universo intelectual alarga-se decisivamente. Lisboa, Paris e Bruxelas aprofundam nele conceitos dinâmicos de existência, liberdade de criação e cumplicidade entre o escritor e a obra, bebidos (no sentido próprio e literal) ao sabor do vento e da desobediência que lhe guiava os passos solitários e errantes de ave de arribação.

Por vezes sinto-me um siriripe feliz, esse passarinho das papaeiras de Angola, que como único defeito tem esta mania de andar a saltitar de ramo em ramo, que é como quem diz, de cidade em cidade,de terra em terra, de emprego em emprego. Como negro vadio. Como marinheiro que gosta de ficar em cada porto que toca, deixando o barco partir, conta nessa primeira recolha das suas crônicas, com prefácio de Artur Queiroz, importante (embora controversa) abordagem do autor e sua época.

O avanço para Brazzaville, no âmbito da opção anticolonialista para que contribuíram tanto a sua vivência e identificação com valores da utopia angolana, como a urgência do viajante de utopias seduzido pelo protagonismo da História que acabou por descambar no regresso ao país pela porta do cavalo, desiludido e amargurado. Irremediavelmente para trás ficava a miragem da luta política organizada, onde não poderia naturalmente caber a sua incontornável inquietude radical.

Uma tábua de presenças tutelares na prosa deste auto angolano que se considerava um brasileiro de Benguela, de pa minhoto, com uma entranhada ternura por Portugal, não pode senão destacar, em primeiro plano, a sombra melancólica ambígüa de Sá de Miranda, de quem tomou os versos por padrầc de comportamento: Farei como os cães do Nilo/ que correm vão bebendo. De Eça, ambição maior, quis tudo herdar, I conseguiu o bastante para nele encontrarmos as mais profunda: incisões intertextuais do estilo que o caracterizou.

Há uma língua portuguesa de antes de Eça e de depois de Eça.(...) Há um português camiliano, sebáceo, cheio de gorduras. antes de Eça, e há o português correndo cristalino como água de um regato, depois de Eça (...) Nada mais surgiu com o seu fulgor. Cristalino, puro, límpido ficou rolando na nossa literatura (...). Tivera nascido francês, inglês, e haveria de ter sido o maior entre os maiores, garantia e apostava. Torga fascinava-o, sabia-o de cor. Mas foi do Brasil que importou a chave-mestra da sua diferença

Intensa e ilimitada, sua freqüência do imaginário brasileiro. Através dele combinou fronteiras, conciliou complementaridades e ergueu um exemplo de surpreendente originalidade. A literatura de Machado de Assis e Mário de Andrade era-lhe intima no essencial e no acessório.Familiar. Ia de Lins do Rego a Graciliano e de Rachel de Queiroz a Jorge Amado, capengando à Garrincha, chutando folhas secas à Didi e defendendo um arco imaginário à Gilmar. Bandeira, especialmente, e Drummond eram visitas de casa.

Quanto aos cronistas, Rubem Braga, em particular, e Fernando Sabino (entre muitos outros), vão ao seu encontro com um projeto bem sucedido para salvar a moderna crônica jornalística do efêmero e precário quotidiano, e conferir-lhe o honrado estatuto de que goza hoje nas literaturas do idioma. Ernesto Lara Filho encarna o modelo, circunstancial mas cheio de encanto poético, que cativa pela simplicidade e agrada pelo tom informal e desafectado, e aduba-o do seu próprio húmus, da sua vertiginosa experiência de crioulo de Angola e cidadão do mundo.

Quando em 1972, Carlos Everdosa vem com inteira justiça "lembrar" aos seus detractores - que acenavam com o figurino brasileiro, procurando diminuir os méritos do escritor, por certo remoendo secretas invejas ou inconfessáveis intolerâncias - que ele " apenas aprendera com os jornalistas do país irmão, como devia fazer uma crônica angolana" (EVERDOSA, 1972), repunha no seu devido lugar o significado desta obra na formação da nossa literatura, onde criou um espaço de confluências tantas quantas soube da vida merecer e realizar.

Não longe da intriga, além das razões invocadas, a constante e sempre reiterada admiração por Gilberto Freyre e o extraordinário impacto de Casa Grande \& Senzala em que reunia as condições ideais para assim acontecer. Contudo, a acusação de não ter sabido resistir às sereias do lusotropicalismo, não cabe ao objecto literário mas ao seu pressuposto, e de resto e já ponto assente o valioso contributo do pernambucano para a leitura da dimensão social e cultural do híbrido.

A partir deste perfil de duas das vertentes fundamentais - de conjunto com a angolana - para o aparecimento da crônica como gênero literário nacional, pela pena do Seripipi, o necessário relance sobre o "background" do intelectual exilado no centro da Europa quando, no princípio dos anos 60 , ali se cruzam todos os desterros, obrigatórios e ieidentais, como requerem o corte de cabelo à Hemingway e o bigode plaçaba que por lá passeou com intenção e "glamour".

De facto, a sua passagem por França e pela Bélgica foi decisiva, a vários títulos, para o jovem "pied-noir", como lhe chamou Mário Antônio: 
"Lembro o amigo/ O pied-noir de Angola /(...) Entusiasmado e desconfiado/Dos que não beberam/ Com ele na Feira Popular " (ANTÓNIO, 1981). O seu horizonte mediático é extraordinariamente enriquecido no contacto direto com o movimento de idéias que impôs o ritmo da autodeterminação e da liberdade de expressão à consciência do século. Sartre, Camus e a Beauvoir moram ao lado.

Paris reverdece em todas as árvores que rebentam para uma primavera florida.Os pardais aparecem aqui perto, nos parques que rodeiam a cidade universitária. Saltitam no Parque de Mountsouris. Os boulevards também começam a ter árvores floridas. As raparigas beijam os rapazes com a maior semcerimônia deste Mundo, nos bancos dos jardins, nos passeios das avenidas, nos subterrâneos do Metro. Beijos demorados, beijos de amor cheirando a primavera que aproxima, que envolve tudo, que nos conquista, saudava em correspondência no $A B C^{2}{ }^{2}$

Entram-lhe pela porta os grandes romancistas da primeira metade do século, com xará Hemingway à cabeça. Lê Caldwell, Steinbeck, Dos Passos. Tolstoi, Dostoievski, Pasternak, Pavese, Malraux, Greene, o melhor Somerset Maugham e por aí fora, devora com paixão os vingadores literários Orwell, Genet, Vian, passa-lhe pelos olhos a melhor imprensa do momento. Não é longa a experiência. Marinheiro de rumo incerto, perde-se no nevoeiro e reaparece na militância activa, aos microfones da Rádio Brazzaville. O rugido do leão da anhara rasga "as florestas impenetráveis do norte" (LARA FILHO, 1989), anunciando os tambores da libertação, como desde aí nunca mais seria ouvido.

O regresso ao interior é marcado pela contribuição política, fatal num jornalista da sua envergadura. Seguido e humilhado pela ação colonial explorado por uns, evitado por outros, amado por poucos,

vocemecês desculpem, leitores, eu queria fazer entrevista reportagem, e saiu feijoada. Vocemecês desculpem, prezado fregueses, mas "óje não á mais passarinhos". O repórter Lar Filho considera-se penhorado e agradecido a todos os clientes que chegaram até aqui. Agradece e retira-se.Baixa o pano.

Aqui e ali assina crônicas que são ainda procuradas, com freqüência na revista Notícia. $^{3}$

É perante o escritor de incontestável qualidade que nof encontramos amiúde. O prosador de primeira água, que arrebatou para at nossas cores um fresco admirável, digno da melhor atenção. Séries come Um Seripipi Angolano e A Independência da Ilha fazem de novo as delícian

${ }^{2} A B C$-DIÁRIO DE ANGOLA, vespertino colonial fundado em 1958 pelo jornalista Machado Saldanha. Publicou-se em Luanda até ao fim dos anos 60 e teve, na sua primeira fase, certa tradichil oposicionista.

${ }^{3}$ NOTÍCIA, semanário colonial fundado em 1959. Tinha formato de revista e era considerado 0 media de melhor nível profissional e maior expansão, na época. dos fiéis. Mas o estigma do desânimo e da autoflagelação, agravado pela corte de sua irmã Alda e o triste desfecho do exílio, minava já, de forma irreversível, o trilho desamparado da sua curta existência.

Joca Luandense, o melhor cozinheiro de calulú - fora de Benguela, é claro - na opinião abalizada do Seripipi, apareceu-me faz pouco na Maianga, sobraçando a idéia. Preto "cabo-verde" (no sentido baiano de negro de cabelo liso), penteado à Nat King Kole, antigo repórter da Tribuna dos Musseques jubilado no Bairro Operário, privou de muito perto com o infalível descobridor de quintais com mesa posta para a funjada de sábado, vinho palheto, pedia luando lá mais para tarde.

Trazia-me uma mão cheia de escritos do amigo comum, resgatadas aos arquivos de seu pai. Dias antes conversáramos casualmente sobre "tio" Ernesto e o vazio que o seu desaparecimento deixou por essa Angola que percorreu de lés a lés e amou com paixão e sofrimento. Sobre a irreverência e a bonomia inconfundíveis, o tom cativante da sua angolanidade enraizada numa simbologia nativa de carácter popular e alcance universal.

A velha S. Filipe de Benguela, que o viu nascer e lhe acalentou a infância que durante toda a vida revisitou incessantemente, resplandece na sua obra como jóia rara, através de uma prosa condimentada no paladar caprichoso do seu mais brilhante cronista, cidade centenária das acácias em flor, das nuvens de martrindindes, da Praia Morena, da Kuribéka, do Pepetela, da bicicleta do Goya, do Camões, do Sombreiro, da Massangarala, da Casa Dá Tempo e dos poemas do Aires de Almeida Santos, que está no céu de intimidade com Nosso Senhor.

Luanda é

a cidade que me deu as maiores alegrias da minha vida. Onde me fiz um boêmio inadiável, nato, constante (...). Onde aprendi a gostar de muzongué e calulú.(...) Onde amei madrugadas cheias de cacimbo, morenas lindíssimas das seis horas no Largo da Mutamba e calemas alterosas nas noites de luar da Ilha do Cabo. Misturo tudo como se isto fosse uma tela impressionista.

Luanda das "receitas de moamba e quimbombo, a terra do sorriso e do requebro das mulatas de olhos cor de dendém".

Ao Huambo, para onde se mudou ainda criança e acabou por morrer num trágico golpe do destino, quando o seu fatigado coração se recusou a prosseguir, já no hospital, após ter embatido, na viatura emprestada em que seguia, ao cair da noite, contra um camião militar mal estacionado e sem luzes, na avenida da Granja - dedicará o texto derradeiro, neluido na mais recente recolha da sua poesia completa (conhecida até a ata), que o situa como um poeta de talento no quadro da sua época.

Chama-se O Canto do Martrindinde (LARA FILHO, 1989)

iegundo a primeira edição dos Cadernos Capricórnios, que o médico e heritor de origem moçambicana, orlando de Albuquerque, viúvo de Alda L ara e radicado entre nós, residindo agora no norte de Portugal, pôs a ireular no início da década de 70, a partir do Lobito, e onde se afirmou ou 
revelou um bom lote de escritores angolanos no activo. Mais a sudeste, no Lubango, o fui conhecer de longas barbas à Fidel espraiando-se sobre uniforme azul de forçado do Forte Roçadas, triste e desiludido da sorte que lhe coube expiar.

Na transição dos anos 60 para 70 , se é verdade que a lenda que encarnava lhe continuou a garantir lugar cativo, como cronista e repórter, entre os melhores quando a tal se dispunha, é indisfarçável, como disse atrás, a sombra de um desencanto de que raro se desprende para o alto vôo, por exemplo, da Guerra de Martrindindes, de 1970, onde o autor se reconcilia com os seus melhores momentos, sobre um tema recorrente na sua obra - a infância, como sublinhei.

Em Coisas de que eu gosto, bastante anterior, inventário breve mas eloqüente de algumas dezenas das suas predilecções, biografia e criaçấo literária confundem-se numa linguagem quase telegráfica, esboço de auto retrato importante em qualquer abordagem. A fórmula utilizada, nada inédita, tem antes a virtude de revelar as fundações de uma atitude radical perante a existência e a escrita, nas suas mais diversas manifestações.

Assim, gosta de

Fumar caricocos. Andar de bicicleta. Namorar morenas. Tomai banho de praia.(...) Dizer poesia. Ver florir os jacarandás e ait buganvílias. Cheiro a terra molhada no princípio das chuvan (...) Saber do nascimento de criança, filha de gente amiga. Come calulú feito por Dona Ema. Pôr gindungo no bife. Dança merengue no sábado. Vinho branco com bolinhos de bacalhau. ( aroma da rosa. O cheiro das violetas. Dar brinquedo a umi criança desconhecida. Afagar uma carapinha.(...) Tocar sanfone dedilhar cavaquinho. Gostar de toda a gente.

E mais adiante:

Oferecer um colar de missangas à bonita escurinha do bairro, Vet o gado pastar o capim novo. Crescer o feijão e o milho na lavra Chá de São Tomé.Café de cigarro, logo pela manhãzinhai(ui Deitar em luando, dormir a sesta no chão. Trepar a cajueire comer cajús. Comer manga, lambuzar com papaia. (...) Viajar de camioneta por essa Angola fora. Café a florir, algodão tambêili (...) Soltar passarinho de gaiola. Sentar em banco de bimbi, ili quintal do amigo. Ensinar menino a ler e a escrever.

Encerrando a

Conversar com boémios até a noite tombar, até naseêf a madrugada. Contemplar um pôr de sol. Viajar para o sul til Angola. Ver caça. Atravessar o Cunene, o Lucala, o Quanza di canoa.(...) Chupar limão. Fresquinho da Samba. Escrever iste
Um rol de inclinações que encadeiam um discurso carregado de sentido, tributário de um código de valores - patrícios, ecológicos, universais - articulados de forma a conferir-lhe carácter semântico e sintático próprios.

Era, como referi, intenção de Joca Luandense e do signatário, coligir um volume de crónicas do Seripipi, como gostava de se autoapelidar, de preferência inéditas em livro, tentando evitar repetir as já publicadas pela Afrontamento, e pô-las ao alcance dos leitores que mal conhecem um dos seus mais talentosos escritores, remetido à penumbra das bibliotecas, entre colecções de jornais amarelecidos.

Acrescentar uma nova ponte na divulgação da obra de Ernesto Lara Filho, só pode ser uma alegria e um gesto em dívida para com quem assinou algumas das melhores páginas da nossa literatura, num género com festejadas tradições no idioma, mas não tem gozado de proporcional atenção. Foi preciso que uma editora portuguesa tomasse a iniciativa de dar a estampa uma boa parte dos textos que esbanjou por jornais e revistas, para se ter acesso a uma visão de conjunto da obra em prosa que nos legou.

Assim surgiu Um Seripipi Angolano e Outras Crônicas, seleção de trabalhos dados à estampa no semanário Notícia, fundado e dirigido até 1967 - quando morreu aos 34 anos - pelo grande amigo João Charulla de Azevedo. Arrumada em duas partes, agrupa a primeira, composições da série homónima, e a segunda, outras avulsas, ao sabor da ocasião, do acaso ou dos problemas de subsistência que ciclicamente perturbavam o seu carismático bom humor.

Desapareceu deste mundo escassos quinze meses após a independência do país natal, quando vigorava um regime autoritário de inspiração soviético-cubana, onde não poderia ter naturalmente assento um espírito livre e irreverente como o seu. Enquanto uma fauna de medíocres (e sirva a carapuça a quem a enfiar) acorriam, solícitos, à tença das sucessivas edições apadrinhadas pela União dos Escritores Angolanos - de que integrou ainda a primeira comissão instaladora - desceu o silêncio sobre o seu nome.

Até 1990, quando saíram a público as Crónicas da Roda Gigante, durante década e meia, portanto, como nação independente, o prosador morou apenas na memória dos poucos admiradores que nunca 0 abandonaram. Seu discurso e comportamento não coincidiam com os padrões da propaganda política. E ainda bem, pois era unânime que a formação da literatura angolana passa pelo seu notável testemunho e pelo jogo intertextual que praticou.

A poesia, marcada pelo élan nacionalista, na esteira e ao estilo discursivo de Agostinho Neto, António Jacinto e Viriato Cruz, a tríade que mais significativamente corporizou o movimento Vamos Descobrir Angola, ideário reivindicativo onde entronca o nascimento da moderna lírica local, logrou, por isso mesmo, atingir a terceira edição. Já com o cronista não se passou o mesmo, nem podia, mal tolerado pelo poder que impôs um Estado policial que ficou para a História sob a designação de I República.

Isso aliado ao facto de se encontrar a obra dispersa, decerto contribuíram para o esquecimento a que foi remetido nos programas 
editoriais que resgataram o rio da literatura nacional em amplas tiragens. É, pois, no sentido de ajudar a colmatar essa lacuna que aparece Um Seripipi Angolano e Outras Crónicas, livro de amigos dispostos a valorizar na justa medida o perfil bibliográfico daquele que foi destacado exemplo da nossa originalidade no quadro da língua portuguesa e das literaturas nela identificadas.

\section{Bibliografia}

ANTÓNIO, Mário. Afonso, o africano. Braga, Pax, 1981.

EVERDOSA, Carlos. Itinerário da literatura angolana. Luanda, Culturang, 1972.

LARA FILHO, Ernesto. Crónicas da roda gigante. Porto, Afrontamento, 1990.

. $O$ canto do martrindinde. $3^{\mathrm{a}} \mathrm{ed}$. Luanda, União dos Escritores Angolanos/Endiama, 1989. 